\title{
PROCESSOS INTERATIVOS EM SALA DE AULA: REFLEXÕES SOBRE A MEDIAÇÃO DA ESCOLA PARA O DESENVOLVIMENTO HUMANO*
}

\section{INTERACTIVE PROCESSES IN THE CLASSROOM: REFLECTIONS ON THE MEDIATION OF THE SCHOOL FOR HUMAN DEVELOPMENT}

\author{
Solange Maria Alves ${ }^{1}$ \\ Gabriele Dullius²
}

Resumo: Com base na teoria histórico-cultural e fruto de reflexões teóricas construídas no exercício da pesquisa de iniciação científica, o presente artigo empreende uma leitura centralizada no desenvolvimento humano, compreendido como conjunto de transformações de ordem cognitiva (e afetivo-volitiva) decorrentes das mediações sociais, simbólicas e culturais, realizadas pelos sujeitos e que promovem nestes, modos de pensamento tipicamente humanos como a atenção voluntária, a memória, a abstração, a generalização, entre outras funções psicológicas superiores. Sob este prisma a escola constitui lócus privilegiado de interações que, realizadas mediante o crivo da ação pedagógica intencional, oferecem um substrato qualitativo fundamental para o desenvolvimento humano. Parte-se do princípio de que o conhecimento é artefato social e, portanto, histórico. E seu aprendizado constitui-se, igualmente, por relações socialmente mediadas que, em última instância, operam, no sujeito, o desenvolvimento de modos complexos de pensamento. Isso significa sublinhar com ênfase o papel do outro e da linguagem como elementos fulcrais de apreensão e produção de conhecimento.

Palavras-chave: Desenvolvimento humano e educação. Interação e aprendizagem. Mediação e processos pedagógicos. 
Abstract: Based on the historical-cultural theory and result of the theoretical reflections, built in the exercise of the research of scientific initiation, this paper undertakes a reading centered on human development, understood as a set of transformations of cognitive (and affective-volitional) deriving from social, symbolic and cultural mediations, performed by the subjects and promote in these, modes typically human as the voluntary attention, memory, abstraction, generalization, among other higher psychological functions. From this perspective, the school is a privileged locus of interactions that, conducted through the sieve of pedagogical intentional action, provide a substrate qualitative necessary to human development. Starting of the principle that knowledge is social artifact and therefore historic. And your learning is also constituted by socially relationships mediated that, ultimately, operate in the subject, the development of complex modes of thought. This means focusing detach emphasizing the role of the other and the language as key elements of apprehension and knowledge production.

Keywords: Human development and education. Interaction and learning. Mediation and pedagogical processes. 
Com base no pressuposto de que o conhecimento é um fenômeno socialmente constituído e a sua apreensão implica uma relação socialmente mediada do sujeito com os objetos, podemos indagar sobre uma teia de possibilidades que nos ajudem a alcançar possíveis respostas aos problemas relativos à aprendizagem e ao ensino tal como protagonizados pelo ambiente escolar. A análise empreendida aqui parte do princípio de que o conhecimento é artefato social e, portanto, histórico. E que o seu aprendizado constitui-se, igualmente, por relações socialmente mediadas que, em última instância, operam no sujeito cognoscente, o desenvolvimento de modos complexos de pensamento (memória, atenção, abstração, projeção, classificação, interpretação etc.). Isso significa sublinhar com ênfase o papel do outro e da linguagem como elementos fulcrais de apreensão e produção de conhecimento.

A partir desta perspectiva, o humano é resultado de um movimento simultâneo e dialético entre quatro planos genéticos de desenvolvimento: a filogênese, que traduz as características biológicas herdadas da espécie; a ontogênese, que se refere ao percurso de desenvolvimento de cada indivíduo da espécie em termos biológicos; a sociogênese, que informa sobre a força da cultura e das relações sociais sobre o desenvolvimento humano; e a microgênese, concebida como campo particular de cada indivíduo, sugere que cada fenômeno psicológico tem sua própria história.

Assim, atingir a condição de ser humano implica mais que simplesmente nascer. É preciso tomar parte do gênero humano, daquilo que é construção social, material e simbólica, feita pela humanidade ao longo da história. E mais, é preciso significar isso como coisa apreendida individualmente. No sentido marxista, como coisa para si. Nesse processo, como aponta a psicologia his- 
tórico-cultural, o trabalho e a linguagem assumem papel preponderante. $\mathrm{O}$ que requer que se observe na linguagem a sua dimensão constituinte do humano (Vigotski), dos seus traços cognitivos, dos seus modos de pensar mediados pelas condições efetivas de vida. A palavra é a expressão mais direta da natureza histórica da consciência humana. "A consciência se reflete na palavra como o sol em uma gota de água." (VIGOTSKI, 2000, p. 496). Isso remete à necessidade de compreender a complexidade das relações sociais nas quais os sujeitos vivem e o significado do lugar por eles ocupado nesta trama.

A significação, quer dizer, a criação e o uso de signos, é a atividade mais geral e fundamental do ser humano, a que diferencia em primeiro lugar o homem dos animais do ponto de vista psicológico. (1995:84). Nos níveis mais altos de desenvolvimento, emergem relações mediadas entre as pessoas. A característica essencial dessas relações é o signo [...] Um signo é sempre, originalmente, um meio/modo de interação social, um meio para influenciar os outros e só depois se torna um meio para influenciar a si próprio. (1995, p. 83)... (O signo) é o próprio meio/modo de articulação das funções em nós mesmos, e podemos demonstrar que sem esse signo o cérebro e suas conexões iniciais não poderiam se transformar nas complexas relações, $o$ ocorre graças a linguagem. (VIGOTSKI, 1996, p. 114 apud SMOLKA, 2004, p. 41, grifos no original).

Para a perspectiva histórico-cultural o conhecimento do mundo é sempre resultado de processos interativos que, por sua vez, constituem-se da materialidade das práticas sociais e culturais, especialmente pela linguagem. É por meio da palavra que os seres humanos emitem, comunicam, classificam, agrupam, recortam, analisam, pronunciam o mundo, o que sentem e o que pensam do 
mundo. A palavra que anuncia o mundo compreendido por sua própria mediação é, contudo, uma palavra marcada, também ela, pela materialidade das práticas sociais. E, por isso, é dita sempre a partir de um lugar histórico e está sempre mediada pelas condições concretas de existência daquele que a emite. A palavra é,

[...] a unidade entre pensamento e linguagem, e porque é explicitação da significação construída na relação homem-mundo, constitui-se, não apenas como instrumento psicológico, mas, também e fundamentalmente, como espaço não neutro onde entram em disputa diferentes visões de mundo, ou seja, como campo ideológico e político. (ALVES, 2012, p. 126).

Mas a palavra, repita-se, não existe como coisa isolada. É signo constituído nas práticas sociais e é, simultaneamente, elemento constituinte dessas práticas que, por sua vez, traduzem formas de relação do ser humano com o universo físico, laboral e cultural. A prática social, mais do que o trabalho humano, é o modo como esse trabalho transforma a vida e produz jeitos de ser e de viver traduzidos em combinações simbólicas, a um só tempo objetivas e subjetivas.

É precisamente na ação sobre o mundo objetivo que o homem se manifesta como verdadeiro ser genérico. Tal produção é a sua vida genérica activa. Através dela, a natureza surge como a sua obra e a sua realidade. Por conseguinte o objecto do trabalho é a objectivação da vida genérica do homem: ao não reproduzir-se apenas intelectualmente, como na consciência, mas activamente, ele duplica-se de modo real e intui o seu próprio reflexo num mundo por ele criado. Pelo que, na medida em que o trabalho alienado subtrai ao homem o objecto de sua produção, furta-lhe igualmente a sua vida genérica, a sua objectividade real 
como ser genérico, e transforma em desvantagem a sua vantagem sobre o animal, porquanto lhe é arrebatada a natureza, o seu corpo inorgânico. (MARX, 1993, grifos no original).

O ser humano sublinha o materialismo histórico e dialético, é feito pelo trabalho, um ser que trabalha. Isso quer dizer que é um ser que inventa, cria, fabrica, constrói e se faz humano pela ação modificadora que exerce sobre a natureza e sobre si mesmo. Mas não faz isso individualmente, pois as transformações que promove na vida natural ou social são ações coletivas. Daí que humanizar-se implica apropriação das objetivações humanas subjetivadas nos objetos feitos pela ação transformadora do próprio ser humano ao longo da história. E esse é um movimento coletivo e criativo. Esse processo se complexifica e se qualifica no surgimento da linguagem, como signo que possibilita a comunicação e a generalização. E demonstra, a um só tempo, que trabalho (ato de criação) e linguagem constituem elementos de humanização, ou seja, geradores de funções psicológicas superiores ou de modos complexos de pensamento (ALVES, 2012).

Sob este prisma, a educação escolar é vista como espaço de interação/comunicação privilegiado em que conhecer constitui-se em um ato de criação recíproca: dos instrumentos, do trabalho e do homem. Assim, essa concepção se revela promissora em termos epistemológicos e metodológicos, quando se trata do processo de elaboração conceitual ou de construção do conhecimento, tal como preconizados pela teoria histórico-cultural: o ato de apreender, elaborar, conhecer, apropriar-se de saberes historicamente produzidos é um ato de criar, um ato necessariamente criativo, um ato de trabalho que, ao criar e construir novas maneiras 
de compreensão e intervenção no real, criam em cada indivíduo a humanidade. No dizer de Saviani (1995), o ato de educar é

[...] o ato de produzir, direta e intencionalmente, em cada indivíduo singular, a humanidade que é produzida histórica e coletivamente pelo conjunto dos homens. Assim, o objeto da educação diz respeito, de um lado, à identificação dos elementos culturais que precisam se assimilados pelos indivíduos da espécie humana para que eles se tornem humanos e, de outro lado e concomitantemente, à descoberta das formas mais adequadas de atingir esse objetivo. (SAVIANI, 1995, p. 21).

Esse é o caráter humanizador do trabalho educativo. Um movimento pedagógico focado na interação social mediadora de possibilidades voltadas à apropriação do gênero e à subjetivação como membro do gênero humano, via processos de ensino e de aprendizagem de conteúdos, procedimentos e atitudes inerentes aos artefatos simbólicos e materiais com quais se faz a educação escolar. É, pois, o trabalho educativo, momento de produção e reprodução da humanidade, isto é, do próprio gênero humano. É esse movimento dialético que assegura as condições de reprodução do indivíduo e da sociedade encarnados um no outro.

É neste sentido que a educação escolar traduz-se em espaço fulcral de desenvolvimento humano. Nela os sujeitos envolvidos no processo de ensino e de aprendizagem protagonizam formas inéditas de interação. Interagir, sob o enfoque colocado, não se reduz a adaptar, mas antes significa dialogar, por em debate conhecimentos, interpretações, análises. E construir sínteses, proposições, tomar decisões, desenvolver soluções para conflitos cognitivos, trocar valores, crenças, comportamentos, de um tal modo único que não se repete em outros espaços. 
O aprendizado escolar, sublinha Vigotski (2000), desempenha papel decisivo no desenvolvimento da elaboração conceitual e na tomada de consciência, pelos sujeitos, de seus próprios processos mentais. Mas esse não é um movimento natural, ou seja, não basta estar na escola para que esses processos mentais ocorram. É preciso que haja, por parte da ação educativa escolar, uma deliberação na direção de atuar decisivamente para este acontecimento. Neste sentido, a intervenção de todo o aparato escolar e, fundamentalmente, da ação docente intencional, assume papel decisivo no processo de humanização que tem no palco das relações escolares seu maior cenário.

Notadamente, ao chegar na escola, o estudante não está vazio de conhecimento, tampouco é alguém que não possua conceitos. Cada indivíduo, desde o nascimento, experimenta um conjunto de relações sociais, culturais, com seus vieses históricos que mediam nele um outro conjunto de possibilidades de desenvolvimento de modos tipicamente humanos de pensar e se comportar. Essa apropriação que aos poucos transforma cada indivíduo num membro do gênero humano, faz-se mediada fundamentalmente pela linguagem. É por meio desse aparato que saberes, valores, modos de ser e de viver são transmitidos, vão sendo internalizados e transformados em coisa para $s i^{3}$. Nesse processo são apreendidos, elaborados conceitos com base em atributos marcados pelo lugar social de cada um seja no âmbito da trama social maior, seja nos espaços dos contextos micro onde, atravessados pelas normas e regulações socioculturais mais amplas, se constroem significações próprias.

Assim, funções psicológicas superiores não são produtos da escolarização, mas são resultados das apropriações feitas na teia de 
relações vividas por cada um. Contudo, a escola é, por excelência, o lugar ao qual socialmente se destina a tarefa de significar, ler e escrever. E, por isso, lugar de desenvolver atenção focada, memória mediada, abstração, reflexão etc., de modo planejado, isto é, intencional. Resulta disso que funções psicológicas superiores desenvolvidas pelo processo de escolarização, apresentam um diferencial básico: são funções psicológicas superiores avançadas cuja gênese e desenvolvimento demanda participação em processos de socialização específicos.

Além disso, vale sublinhar, corroborando com Baquero (1998) e Vigotski (1994), a principal via de formação subjetiva e, em decorrência de funções psicológicas superiores, é a via da intersubjetividade e da interiorização. Toda a operação psicológica, insistem as teses vigotskianas, origina-se e constitui-se no plano das interrelações, ou seja, no plano intersubjetivo e, depois, no intrassubjetivo, isto é, como competência, habilidade, saber próprio do sujeito. Esse movimento é responsável pela humanização (compreendida como apropriação e desenvolvimento de processos psicológicos superiores). Contudo, a interiorização não se reconhece como cópia ou mera reprodução de experiências ou saberes. Trata-se antes de um processo complexo e dialético, com continuidades e rupturas, que se detém, interrompe-se, avança.

É por isso que, no âmbito do ensino e da aprendizagem escolar, o estudante que aprende o ensinado não o faz de uma vez só. Não apropria o conceito de forma pronta, acabada. Precisa compreender, ver de novo, lidar com esse conceito de diferentes jeitos, apropriar os atributos que compõe o conceito e, principalmente, elaborar num processo dialógico onde possa propor e testar hipóteses, argumentar, indagar, problematizar, concordar, discordar, 
relacionar, transformar em coisa sua e, portanto, como todos os meandros do campo microgenético, aquilo que gera humanidade. Assim, parafraseando Vigotski (2000), ao tratar do processo de assimilação do significado da palavra, o aprendizado de um conceito é, na verdade, o começo do aprendizado e, por consequência, de possibilidades de desenvolvimento de formas mais complexas, tipicamente humanas, de funcionamento cognitivo.

Nossa análise modifica a visão tradicional, segundo a qual, no momento em que a criança assimila significado de uma palavra, ou domínio de uma operação tal como a adição ou a linguagem escrita, seus processos de desenvolvimento estão basicamente completos. Na verdade, naquele momento, eles apenas começaram. (VIGOTSKI, 2000, p. 118).

Cabe observar ainda que, em sendo a linguagem um elemento central dos processos interativos que promovem em cada indivíduo a humanidade e em sendo essa promoção um fato sempre social, tem-se que a linguagem, e nela a palavra, não pode ser outra coisa senão um signo feito na concreticidade das relações sociais. Daí que conhecer as elaborações já efetivadas no sujeito (estudante) implica conhecer o lugar social de onde o sujeito emite a sua palavra.

[...] a experiência social constituinte da subjetividade é uma experiência marcada pelas determinações históricas, pelas circunstâncias históricas, que, em larga escala, demarcam os territórios sociais e as possibilidades individuais de acesso ao saber universal. O que não significa, nos parâmetros da abordagem histórico-cultural, uma distinção entre melhores e piores formas de funcionamento intelectual. Mas, seguramente, implica a observância das diferenças cognitivas que se constituem a partir das trocas sociais vividas pelos sujeitos e que se manifestam pela sua palavra, 
pela significação construída nos processos interativos que ocorrem tanto do indivíduo com os artefatos materiais e simbólicos presentes na cultura em geral quanto na relação com o outro. (ALVES, 2012, p. 170).

Daí que

Os sentidos de uma palavra não existem em si mesmos, como algo já dado. Eles são elaborados nas enunciações concretas (que são a unidade da língua, quer se trate de discurso interior ou exterior). As enunciações são sempre parte de um 'diálogo social ininterrupto'. Os interlocutores têm sempre um horizonte social e uma audiência que configuram as trocas verbais de acordo com as diversas esferas da prática social. A significação carrega consigo as marcas dessas condições sociais. (FONTANA, 2000, p. 25).

A palavra dita e sua significação, como elementos que concorrem fortemente para o processo de constituição da subjetividade humana, traduzem em grande medida as possibilidades de desenvolvimento psíquico dos sujeitos que a pronunciam. E, em sendo a sala de aula um lugar de encontro de subjetividades e sendo a escola o lugar social destinado à apropriação do conhecimento e de formas de pensamento construídos pela humanidade, é ali, também, que o uso da palavra grávida de vida se faz instrumento mediador de modos complexos de pensar e ser por meio da organização deliberada dos tempos e espaços destinados a esse fim.

Decorre disso, uma vez mais, a necessária valorização e fomento de processos interativos em sala de aula, por intermédio dos quais estudantes e docentes comuniquem, dialoguem e construam novas aprendizagens. E mais, sob esse prisma teórico, o ensino como tarefa primeira da escola constitui espaço-tempo estratégico de auditoria e de audiência de si mesmo como ferramenta 
de desenvolvimento humano. Estudantes, com suas experiências sociais e culturais, suas crenças, valores e modos de interpretar a vida, demandam salas de aula abertas à audição dessa experiência e a mediações de outras formas de compreensão. Mas, ouvir estudantes é compreendê-los

[...] nas mais variadas dimensões de sua prática na prática social de que fazem parte. Sua fala, sua forma de contar, de calcular, seus saberes em torno do chamado outro mundo, sua religiosidade, seus saberes em torno da saúde, do corpo, da sexualidade, da vida, da morte, da força dos santos, dos conjuros. [...] O respeito a esses saberes se insere no horizonte maior que eles se geram - o horizonte do contexto cultural, que não pode ser entendido fora do seu corte de classe, até mesmo em sociedades de tal forma complexas em que a caracterização daquele corte é menos facilmente apreensível. [...] a localidade dos educandos é o ponto de partida para o conhecimento que eles vão criando do mundo. 'Seu' mundo, em última análise é a primeira e inevitável face do mundo mesmo. (FREIRE, 2003, p. 86 , grifos nossos).

Neste contexto e frente à mediação pedagógica deliberada, cada educando é colocado diante da tarefa particular de "entender" as bases dos sistemas de concepções científicas, as quais requerem a utilização e de operações mentais lógicas que, no âmbito do processo de ensino e de aprendizagem escolar, impulsionam o desenvolvimento da cognição e da consciência reflexiva dos estudantes.

A escola, como instituição social, é o espaço tempo cuja tarefa principal é o ensinar e o aprender. E isso implica o reconhecimento da inter-relação e funcionalidade desses dois polos. Então, mesmo tendo sido e estar sendo ao longo da história, um lugar de atendimento de necessidades advindas de situações de vulnerabilidade social e afetiva (fome, pobreza, violência, salas cheias, 
agressividade, apatia etc.), a escola, lembra Libâneo (2004), ainda que num contexto de globalização e aceleração da vida, fruto dos inventos humanos nas suas várias facetas,

[...] continua sendo lugar de mediação cultural, e a pedagogia, ao viabilizar a educação, constitui-se como prática cultural intencional de produção e internalização de significados. O modus faciendi da mediação cultural, pelo trabalho dos professores, é o provimento aos alunos dos meios de aquisição de conceitos e de desenvolvimento de capacidades cognitivas e operativas, dois elementos da aprendizagem escolar interligados e indissociáveis. (LIBÂNEO, 2004, p. 6).

Sob este prisma, a escola constitui espaço privilegiado de desenvolvimento humano. Significa afirmar esse lugar de ensinar e de aprender como o campo onde, por meio das mediações, das interações, dos processos comunicativos, de troca, de construção de argumentos e negociação de sentidos e significados, colocam-se em movimento, em cada sujeito protagonista, modos de organização cognitiva mais complexos. No dizer de Vigotski, modos tipicamente humanos de pensamento ou funções psicológicas superiores, como a atenção voluntária, a memória mediada, a reflexão, a classificação, o planejamento, o pensamento estratégico.

Então, sendo a escola lugar de ensinar e de aprender, a maior responsabilidade sobre o desenvolvimento de funções superiores de pensamento, é de quem tem como função primordial o ensino. Ensinar, ensina Freire, exige competência profissional, generosidade, comprometimento, liberdade e autonomia, reconhecer a educação como instrumento de transformação e de intervenção no mundo, tomada consciente de decisões, planejamento e intencionalidade. Ensinar exige saber ouvir, querer bem aos educandos, ter fé no ser humano. 
Vigotski, ao longo de sua obra, explicita a relevância da escolarização para a apropriação de conceitos científicos e para o desenvolvimento de capacidades de pensamento pela via da assimilação da produção cultural da humanidade. Ao aprender, no processo de conhecimento, o sujeito, a um só tempo, toma para si, para seu domínio, o conteúdo historicamente acumulado e desenvolve-se como gênero humano, ou seja, apropria-se de modos especificamente humanos de funcionamento psicológico. Para este pensador,

[...] a aprendizagem e o ensino são formas universais de desenvolvimento mental. $\mathrm{O}$ ensino propicia a apropriação da cultura e desenvolvimento do pensamento, dois processos articulados entre si, formando uma unidade. Podemos expressar essa idéia de duas maneiras: a) enquanto o aluno forma conceitos científicos, incorpora processos de pensamento e vice-versa. b) enquanto forma o pensamento teórico, desenvolve ações mentais, mediante a solução de problemas que suscitam a atividade mental do aluno. Com isso, o aluno assimila o conhecimento teórico e as capacidades e habilidades relacionadas a esse conhecimento. (LIBÂNEO, 2004, p. 7).

É por isso que, neste enfoque teórico, diz-se que a aprendizagem está à frente dos processos de desenvolvimento. Essa tese vigotskiana deriva, ainda, de sua concepção acerca do papel da aprendizagem no desenvolvimento humano. Para ele, muito embora se caracterizem como processos interdependentes, a aprendizagem - compreendida como espaço de diálogos, de trocas, de desafios, de argumentação, de interação, de mediação - constitui um terreno fértil, através da qual se mobilizam processos de desenvolvimento cognitivo-afetivo em vias de emergirem. Do ponto de vista vigotskiano: 
[...] aprendizado não é desenvolvimento; entretanto, o aprendizado adequadamente organizado resulta em desenvolvimento mental e põe em movimento vários processos de desenvolvimento que, de outra forma, seriam impossíveis de acontecer. Assim, o aprendizado é um aspecto necessário e universal do processo de desenvolvimento de funções psicológicas culturalmente organizadas e especificamente humanas. (VIGOTSKI, 1994, p. 118, grifo nosso).

Quanto mais organizada, planejada, intencional é a ação de ensino em termos cognitivos e afetivos, mais essa ação é promotora de possibilidades de aprendizagem de conteúdos e de modos complexos de pensamento.

Outro elemento importante a ser destacado diz respeito aos vínculos afetivos inerentes aos processos interativos e comunicativos em sala de aula. De modo genérico, quando se fala em afeto a primeira impressão é a de que a boa ação pedagógica é a que se pauta em vínculos não diretivos em ser "bonzinho", em deixar que os estudantes façam por conta própria sem intervir ou coisa parecida. Quando isso acontece, via de regra, tem-se um processo interativo que resulta em desorganização da ação dos estudantes e, como consequência, uma desordem cognitiva alimentada pela ausência de intencionalidade e de regras claras para a relação entre ensino e aprendizagem.

Isso denota a necessidade de comando nessa relação. O que não quer dizer autoritarismo, rigidez excessiva ou desrespeito ao modo de ser, de viver e de conhecer dos educandos. Trata-se do que Freire chama de amorosidade, que tem a ver com dialogicidade crítica. E ser dialógico “[...] é vivenciar o diálogo. Ser dialógico é não invadir, é não manipular, é não sloganizar. Ser dialógico é empenhar-se na transformação constante da realidade." (FREIRE, 1983, p. 28). 
E, adiante, insiste o autor: "O que se pretende com o diálogo, em qualquer hipótese [...], é a problematização do próprio conhecimento em sua indiscutível relação com a realidade concreta na qual se gera e sobre a qual incide, para melhor compreendê-la, explicá-la e transformá-la." (FREIRE, 1983, p. 28, grifo nosso).

Ainda, no dizer de Alves (2012, p. 243),

[...] na interatividade da sala de aula, o processo pedagógico intencionalmente voltado para o fomento do desenvolvimento de formas complexas de pensamento, não pode ignorar os sentidos construídos pelos sujeitos na sua trajetória de vida. E, porque são sentidos construídos na experiência histórica, retratam crenças, afetos, modos de ser e de viver que demandam do ato de ensinar o respeito, a humildade, a amorosidade, o saber ouvir, a rigorosidade metódica, o bom senso, a generosidade, a seriedade e o compromisso com um processo de construção do conhecimento capaz de conscientizar, tanto no sentido psicológico, que essa expressão pode assumir, quanto como ato pedagógico em favor da libertação humana.

Pode-se inferir, assim, que cognição e afeto são coisas inseparáveis e que, quanto mais claras estiverem as regras das interações afetivo cognitivas, melhor fluirá o processo de aprendizado e de desenvolvimento de modos complexos de pensamento, tarefa precípua da escola. Além disso, estudar os processos de interação entre pares, buscar compreender como o estudante se comporta frente a uma atividade de aprendizagem, implica vê-lo em relação com o ensino e com quem está à frente do ato de ensinar. É impossível ler as interações dos estudantes sem a interação entre estes e a docência.

Desse modo, pode-se dizer, com alguma segurança, que o sucesso escolar, em termos de aprendizagem efetiva, carece, entre 
outras coisas, de clareza acerca do que aprender, por que aprender, para que aprender e como aprender que, por sua vez, implica reflexão sobre o que ensinar, por que ensinar e para que ensinar o que ensinar. Como alerta Vigotski:

\begin{abstract}
É absolutamente indubitável, indiscutível e irrefutável o fato de que a tomada de consciência e a arbitrariedade dos conceitos, propriedades não inteiramente desenvolvidas dos conceitos espontâneos do aluno escolar, situam-se inteiramente na zona de seu desenvolvimento imediato, ou seja, revelam-se e tornam-se eficazes na colaboração com o pensamento do adulto. Isso nos explica tanto o fato de que o desenvolvimento dos conceitos científicos pressupõe um certo nível de elevação dos conceitos espontâneos, no qual a tomada de consciência e a arbitrariedade se manifestam na zona desenvolvimento imediato, quanto o fato de que os conceitos científicos transformam e elevam ao nível superior os espontâneos, concretizando a zona de desenvolvimento imediato destes: porque o que a criança hoje é capaz de fazer em colaboração, amanhã estará em condições de fazer sozinha. (VIGOTSKI, 2000, p. 351, grifos nossos).
\end{abstract}

Assim, quanto mais clara for a intencionalidade do ensino, tanto em seu conteúdo quanto na estratégia de aprendizagem adotada, mais chances de desenvolvimento efetivo de modos complexos de pensamento se colocam. Quanto mais claros estiverem os conceitos, as grandes categorias a serem apreendidas pelos estudantes e quanto mais se organizarem tempos e espaços de argumentação, troca, reflexão orientada, mais os processos interativos se transformam em ferramentas de internalização de reorganização cognitiva e, portanto, melhor é o papel da aprendizagem no desenvolvimento de funções psicológicas superiores. 


\section{Referências}

ALVES, Solange Maria. Freire e Vigotski: um diálogo entre a pedagogia freireana e a psicologia histórico-cultural. Chapecó: Argos, 2012.

BAQUERO, Ricardo. Vygotsky e a aprendizagem escolar. Porto Alegre: Artes Médicas, 1998.

FONTANA, Roseli C. Mediação pedagógica na sala de aula. 3. ed. Campinas: Autores e Associados, 2000.

; CRUZ, Nazaré. Psicologia e Trabalho Pedagógico. São Paulo: Atual, 1997.

FREIRE, Paulo. Extensão ou comunicação. 8. ed. Rio de Janeiro: Paz e Terra, 1983.

Pedagogia da esperança: um reencontro com a pedagogia do oprimido. 10. ed. Rio de Janeiro: Paz e Terra, 2003.

FRIGOTTO, Gaudêncio. O enfoque da dialética materialista na pesquisa educacional. In: FAZENDA, Ivani (Org.). Metodologia da Pesquisa Educacional. 3. ed. São Paulo: Cortez, 1994.

GÓES, Maria Cecília Rafael de. A abordagem microgenética na matriz histórico-cultural: uma perspectiva para o estudo da constituição da subjetividade. Cadernos Cedes: Relações de ensino - análises na perspectiva histórico-cultural, Campinas, n. 50, 2000.

KOSIK, Karel. Dialética do Concreto. 2. ed. Rio de Janeiro: Paz e Terra, 1976.

LIBÂNEO, José Carlos. A didática e a aprendizagem do pensar e do aprender - Davidov e a teoria histórico-cultural da atividade. Revista Brasileira de Educação, n. 23, p. 6-24, set./out./nov./dez. 2004.

MARX, Karl. Manuscritos econômico-filosóficos. Lisboa: 70, 1993.

OLIVEIRA, Marta Kohl. Organização conceitual e escolarização. In: OLIVEIRA, Marcos Barbosa de; OLIVEIRA, Marta Kohl de (Orgs.). 
Investigações cognitivas: conceitos, linguagem e cultura. Porto Alegre: Artes Médicas, 1999.

. Três questões sobre desenvolvimento conceitual. In: OLIVEIRA, Marcos Barbosa de; OLIVEIRA, Marta Kohl de (Orgs.). Investigações cognitivas: conceitos, linguagem e cultura. Porto Alegre: Artes Médicas, 1999.

Vygotsky: desenvolvimento e aprendizado um processo sóciohistórico. São Paulo: Scipione, 1993.

PALANGANA, Isilda C. A função da linguagem na formação das consciências. Cadernos Cedes: Implicações pedagógicas do modelo histórico-cultural, Campinas, n. 35, 2000.

. Desenvolvimento e Aprendizagem em Piaget e Vygotsky: a relevância do social. São Paulo: Pléxus, 1994.

REGO, Teresa C. Vygotsky: uma perspectiva histórico-cultural da educação. Petrópolis: Vozes, 1995.

SAVIANI, D. Pedagogia histórico-crítica: primeiras aproximações. 5. ed. São Paulo: Autores Associados, 1995.

SMOLKA, Ana B. Sobre significação e sentido: uma contribuição à proposta de rede de significações. In: ROSSETTI-FERREIRA, M. C.; AMORIN, K. S.; SILVA, A. P. S.; CARVALHO, A. M. A. (Orgs.). Rede de significações e o estudo do desenvolvimento humano. Porto Alegre: Artes Médicas, 2004. v. 1. p. 35-49.

VIGOTSKI, L. S. A Construção Pensamento e Linguagem. São Paulo: Martins Fontes, 2000.

. A Formação Social da Mente. São Paulo: Martins Fontes, 1994. 


\section{Notas}

* A reflexão teórica empreendida aqui é fruto de pesquisa financiada pelo CNPq por meio do PIBIC 2011. Realizada numa escola de ensino médio do oeste de Santa Catarina, pertencente à rede pública estadual de ensino, que procurou caracterizar os processos interativos/comunicativos em sala de aula e o desenvolvimento de modos complexos de pensamento tal como definidos pela teoria histórico-cultural de desenvolvimento humano.

${ }^{1}$ Doutora em Educação pela USP. Professora da Universidade Federal da Fronteira Sul, campus Chapecó (SC). Orientadora da referida pesquisa. E-mail: <solange.alves@uffs.edu.br>. Telefone: (49) 9913-2456.

2 Aluna do curso de Pedagogia da Universidade Federal da Fronteira Sul, campus Chapecó (SC), e bolsista do PIBIC 2011. E-mail: <gabi_psk@hotmail. com>.

${ }^{3}$ Expressão cunhada por Karl Marx numa referência à tomada de consciência pelos dos seres humanos, de suas condições concretas de existência e possibilidades de transformação histórica. 